\title{
Identification by Integrated Computer Modeling and Light Scattering Studies of an Electrostatic Serum Albumin-Hyaluronic Acid Binding Site
}

\author{
Kristopher R. Grymonpre,$^{\dagger}$ Bethany A. Staggemeier,‡ Paul L. Dubin, ${ }^{*} \S$ and \\ Kevin W. Mattison" \\ Department of Chemistry, Indiana University-Purdue University, Indianapolis, Indiana 46202-3276, and \\ Department of Chemical Engineering, Massachusetts Institute of Technology, \\ Cambridge, Massachusetts 02139-4307
}

Received December 29, 2000; Revised Manuscript Received March 28, 2001

\begin{abstract}
Dynamic light scattering and turbidimetry, carried out on solutions of hyaluronic acid (HA) and bovine or human serum albumin (SA) at fixed ionic strength $(I)$, revealed a critical $\mathrm{pH}$ corresponding to the onset of HA-SA soluble complex formation. Subsequent reduction of $\mathrm{pH}$ below $\mathrm{pH}_{\mathrm{c}}$, corresponding to an increase in protein net positive charge, results in phase separation of the complex. The sensitivity of $\mathrm{pH}_{\mathrm{c}}$ to $I$ indicated the primacy of electrostatic interactions in this process. Since $\mathrm{pH}_{\mathrm{c}}$ was always above the $\mathrm{p} K_{\mathrm{a}}$ of HA, these effects could be attributed to the influence of protein charge. The electrostatic potential around HSA was modeled using DelPhi (MSI) under pH, I conditions corresponding to incipient binding, phase separation, and noninteraction. At all incipient binding conditions (i.e., $\mathrm{pH}_{\mathrm{c}}$, at varying $I$ ), an identical region of positive potential $5 \AA$ from the protein van der Waals surface appeared. This unique domain intensified with a decrease in $\mathrm{pH}$ or $I$ (corresponding to stronger binding), and diminished with an increase in $\mathrm{pH}$ or $I$ (i.e., at noninteracting conditions). The size and low curvature of this domain could readily accommodate a 12 $\mathrm{nm}$ (decamer) sequence of HA. Simple electrostatic considerations indicate an electrostatic binding energy for the formation of this complex of ca. $1 \mathrm{kT}$, consistent with the condition of incipient complex formation. We suggest that such weak electrostatic binding may characterize nonspecific interactions for other proteingylcosaminoglycan pairs.
\end{abstract}

\section{Introduction}

Globular proteins interact with both natural and synthetic polyelectrolytes, but the respective literatures on these two types of systems are highly segregated, as are the objectives and strategies of investigation. With regard to motivations, the focus of studies with biological systems has been on DNA-binding proteins, where the wealth of molecular detail developed is mainly directed toward elucidation of storage, transcription, and recognition mechanisms, with only a few recent studies on the general physical chemistry of the interaction. ${ }^{1}$ On the other hand, investigations involving proteins and synthetic polyelectrolytes, where extensive early studies established the general properties of soluble and insoluble complexes, ${ }^{2}$ have been concerned less with the mechanisms of biological phenomena and more with biotechnological applications, such as protein purification, ${ }^{3}$ enzyme immobilization, ${ }^{4}$ and immunosensing ${ }^{5 a-c}$ and bioactive sensors. ${ }^{5 \mathrm{~d}}$ The techniques and objectives of investigation are also different. In studies of DNA-protein interactions, methods such as NMR, ${ }^{6}$ gel mobility shifts, ${ }^{7}$ photoaffinity labeling, ${ }^{8}$ fluorescence spectroscopy, ${ }^{9}$ and footprinting ${ }^{10}$ were

\footnotetext{
† Massachusetts Institute of Technology.

$\doteqdot$ Current address: Department of Chemistry, University of Washington, Seattle, WA 98195-1700.

$\S$ Indiana University-Purdue University.

"Current address: Protein Solutions, Inc., Charlottesville, VA 229032858.
}

used to identify binding domains and to characterize conformational changes that accompany binding. In contrast, for studies with abiotic systems, physicochemical techniques ${ }^{11}$ such as light scattering, ${ }^{12}$ electrophoresis, ${ }^{13}$ viscometery, ${ }^{11}$ fluorescence quenching, ${ }^{14}$ potentiometry, ${ }^{15}$ and capillary electrophoresis ${ }^{16}$ have been employed to characterize, e.g., the number of proteins bound per polymer chain, the energetics of binding, and the compactness of the complexes. Differences between the two fields also arise because interactions between proteins and DNA are high affinity, siteand sequence-specific, and hence selective, and moreover draw their significance from the vast interplay of processes involved in transcription and genetic expression. In contrast, interactions between proteins and synthetic polyelectrolytes with molecular structures and chain conformations that are very simple compared to DNA are relatively nonspecific and characterized by low-affinity binding.

While these distinctions justify distinguishing between DNA-protein interactions and synthetic polyelectrolyteprotein complexation, this separation is less appropriate in regard to the properties and functions of glycosaminoglycans (GAGs). Heparin and heparan sulfate, dermatan sulfate, chondroitin sulfate, and hyaluronic acid are strongly anionic polysaccharides known primarily as components of proteoglycans (PGs). Previously thought to participate mainly in structural/mechanical tasks in the extracellular matrix or in synovial and intraocular fluids such as adhesion, lubrica- 
tion, and filtration, ${ }^{17}$ PGs are now seen as also essential to intercellular signaling and cell development. ${ }^{18}$ These multiple functions might correspond to PG structural diversity, e.g., variations of core proteins ${ }^{19}$ and in the length and composition of oligosaccharide chains. But, arguably, "the structural commonality among PGs underlies some shared aspects of function". ${ }^{20}$

In contrast to DNA, GAGs in aqueous media have no discernible secondary or tertiary structure, resembling "random coil" (flexible chain) polyelectrolytes. Recent studies ${ }^{20}$ question the significance of sequence-specific, high-affinity protein/GAG interactions, suggesting instead that lowaffinity, nonspecific interactions may be central to the regulatory role of GAGs. Techniques grounded in the assumption of specific binding dictated by highly evolved protein structural units seem to lead to ambiguous results. For example, enzymatic cleavage of heparin (Hp) leads to the identification of a variety of oligosaccharides with high affinity for antithrombin ("the prototypic heparin-binding protein"). ${ }^{21}$ A complex of fibroblast growth factor (FGF) and an $\mathrm{Hp}$ pentasaccharide can be crystallized and a "binding site" identified, ${ }^{22}$ but this approach may fail to reflect chain conformational constraints of polymeric $\mathrm{Hp}$ and its sequence heterogeneity (there are, for example, in principle $10^{5}$ different Hp hexasaccharides). A specific antithrombin (AT)binding saccharide sequence can be identified in some Hp molecules, ${ }^{20}$ but isolated heparin subfractions with strong AT binding affinity exhibit overall an increase of affinity with molecular weight and charge content with no clear identification of a common sequence "motif". ${ }^{21}$ And fibronectin was reported to have six active binding sites for Hp. ${ }^{23}$ These results suggest that we consider GAG-protein binding in terms of nonspecific interactions, dominated by long-range electrostatic forces. For complexation of proteins with synthetic polyelectrolytes, this viewpoint is supported by the observed effects of electrolyte and polymer charge density. ${ }^{24}$ Also, a double-logarithmic dependence of binding constant on ionic strength, long taken as evidence for the electrostatic component of DNA-ligand complexation, ${ }^{25}$ has been observed for GAG-protein or -polypeptide systems. ${ }^{26}$

Both experiments and modeling for GAGs are complicated by their molecular weight and compositional heterogeneity. GAG sequence heterogeneity arises biosynthetically primarily via incomplete postpolymerization enzymatic deacylation and sulfation reactions. The sole exception is hyaluronic acid, the backbone of extracellular, collagen-associated PGs, which consists of a single repeating disaccharide unit containing one carboxylic acid. Sequence-specific protein binding is thus unlikely. While short-range interactions due to hydrophobic and van der Waals forces are intrinsic to site-specific recognition of true biochemical cognates, the binding between HA and proteins is more likely to involve long-range Coulombic interactions. HA-protein systems may therefore be a paradigm for nonspecific complexation between proteins and biological polyelectrolytes.

HA is the major component of synovial fluid, essentially a dialyzate of serum ${ }^{27}$ that contains numerous proteins; these may complex with HA and thereby influence its rheological properties, ${ }^{28}$ consequently affecting joint lubrication and its deterioration in osteoarthritis. ${ }^{27}$ Since HA and serum albumin are both of high molecular weight $\left(1 \times 10^{6}\right.$ and $7 \times 10^{5}$, respectively), their interaction is easily monitored by light scattering. Previous studies of synthetic polyelectrolyteprotein systems by such methods, ${ }^{11,14,24}$ in addition to fluorescence spectroscopy ${ }^{29}$ and electrophoretic light scattering, ${ }^{30}$ all reveal a critical $\mathrm{pH}$ for complex formation independent of protein or polymer concentration, depending only on ionic strength. Since we find $\mathrm{pH}_{\mathrm{c}}$ for $\mathrm{HA}$ and serum albumin to be always above the $\mathrm{p} K_{\mathrm{a}}$ of $\mathrm{HA},{ }^{31}$ we may consider HA as fully ionized, and therefore interpret changes in $\mathrm{pH}_{\mathrm{c}}$ in terms of protein charge state alone.

The observation of $\mathrm{pH}_{\mathrm{c}}$ "on the wrong side of the isoelectric point", ${ }^{11}$ often seen for protein-synthetic polyelectrolyte systems, suggests the existence of a local protein domain with an effective charge opposite in sign to net protein charge. The importance of such "charge patches" has long been recognized in protein chromatography, ${ }^{32}$ but their identification is by no means clear. Here we attempt to define the location of the domain governing the binding of serum albumin to HA by combining experimental results with protein computer modeling. Identification of protein binding sites has indeed been one of the principal goals of computer modeling and the objective of some more recent programs (e.g., DOCK, GRID, etc.). ${ }^{33}$ Such computational procedures were recently applied to the "docking" of heparin to FGF, AT, and Interleukin-823, wherein the authors perceptively stated that "the weak surface complementarity, the high charge density of heparin, and the highly flexible nature of the GAG chain" complicate this task. ${ }^{33}$ Therefore, in that study, both computational procedures and the crystallographic data used to evaluate them were restricted to specific hexasaccharides, with the result that the effects of polymer chain configurational entropy and the possibility of extensive hydration were eliminated from both the docking protocols and the crystallographic reference points.

Since the hydration and stiffness ${ }^{34}$ of HA essentially preclude the intimacy of approach typical of highly selective ligand-binding, potential functions that focus on dipole interactions, hydrogen bonding, and hydrophobicity are not particularly relevant, and we turn to electrostatic protein modeling, using "DelPhi". Early versions of this program solved the linearized Poisson-Boltzmann equation to obtain the electrostatic potential around proteins. ${ }^{35}$ Recent reports describe numerical solutions of the PBE, using fast algorithms in DelPhi, ${ }^{36}$ and greater accuracy attained by solving the nonlinear PBE without the assumption of low potential. ${ }^{37}$ Detailed literature on the $\mathrm{pH}$ titration of serum albumin ${ }^{36 \mathrm{a}}$ along with its inclusion in the protein database ${ }^{38}$ facilitates these electrostatic calculations.

Our strategy relies on the identification of critical conditions for complexation similar to those found for a number of protein-synthetic polyelectrolyte pairs. The following criteria should be applicable: (1) Since $\mathrm{pH}_{\mathrm{c}}$ corresponds to incipient binding, computer electrostatic modeling might be expected to reveal the same "charge patch" at $\mathrm{pH}_{\mathrm{c}}$ regardless of $I$, since all critical conditions should entail the same binding energy. (2) Variation of $\mathrm{pH}$ away from $\mathrm{pH}_{\mathrm{c}}$, in the direction of either noninteracting conditions or phase separa- 
tion, should result in, respectively, diminution or expansion of the positive-potential binding domain. (3) The binding energy at $\mathrm{pH}_{\mathrm{c}}$ should be on the order of thermal energy, since this is the condition for the onset of binding.

\section{Experimental Section}

Materials. Bovine serum albumin (24H0177) and human serum albumin (66H9306) were obtained from Sigma Chemical Co. (St. Louis, MO) and were used without further purification. Hyaluronic acid sodium salt (NaHA, MW 1.2 $\times 10^{6}$ ), produced by bacteria and purified by filtration through activated charcoal, was supplied by Shiseido Co. (Japan). Hydrochloric acid and sodium hydroxide were purchased from Sigma and were $99.5 \%$ pure or better. Sodium chloride was purchased from Fisher Scientific (Pittsburgh, PA). All water was deionized and filtered (0.2 $\mu \mathrm{m}$ Millipore).

Turbidimetric Titration. Protein and polymer solutions were prepared in the appropriate buffer or salt solutions prior to filtration $(0.45 \mu \mathrm{m}$ Whatman filters). Protein solutions were used the day of preparation, and HA solutions were stirred overnight to ensure complete solubilization. Turbidimetric titrations were performed using a Brinkmann PC 800 probe colorimeter with a $420 \mathrm{~nm}$ interference filter and a $2 \mathrm{~cm}$ path length probe at $22 \pm 0.5^{\circ} \mathrm{C}$; the transmittance (T) was set to $100 \%$ in deionized water. Probe drift was less than $0.2 \% T$ over the time of the titration. $\mathrm{pH}$ was monitored with a Corning 240 meter equipped with an Orion combination probe and calibrated with $\mathrm{pH} 4$ and 7 buffers. Solutions of $0.5 \mathrm{~g} / \mathrm{L}$ protein $+0.05 \mathrm{~g} / \mathrm{L}$ HA in varied concentrations of $\mathrm{NaCl}$ were adjusted to $\mathrm{pH} 8$ with sodium hydroxide and then titrated with $0.1 \mathrm{M} \mathrm{HCl}$ using a $2.0 \mathrm{~mL}$ Gilmont microburet, to obtain the dependence of the turbidity (proportional to $100-\% T$ ) as a function of $\mathrm{pH}$. Discontinuities in these plots revealed the points of initial complex formation $\left(\mathrm{pH}_{\mathrm{c}}\right)$ and subsequent phase separation $\left(\mathrm{pH}_{\phi}\right)$, respectively.

Dynamic Light Scattering (DLS). Samples filtered through a $0.1 \mu \mathrm{m}$ Whatman filter were analyzed with a DynaPro-801 DLS instrument (Protein Solutions, Inc., Charlottesville, VA) equipped with a $30 \mathrm{~mW}$ solid state $790 \mathrm{~nm}$ laser. The intensity of light scattered from the $7.0 \mu \mathrm{L}$ cell was detected by an avalanche photodiode detector at $90^{\circ}$ scattering angle. The mean apparent translational diffusion coefficient $\left(D_{\mathrm{T}}\right)$ was determined by fitting the autocorrelation function using the method of cumulants. The hydrodynamic radius $\left(R_{\mathrm{h}}\right)$ of particles was determined from the StokesEinstein equation

$$
R_{\mathrm{h}}=k_{\mathrm{b}} T / 6 \pi \eta D_{\mathrm{T}}
$$

where $k_{\mathrm{b}}$ is Boltzmann's constant, $T$ is the temperature $(\mathrm{K})$, and $\eta$ is the solvent viscosity. The critical $\mathrm{pH}$ was determined as the $\mathrm{pH}$ at which both scattering intensity and particle radius initially increased. The $\mathrm{pH}$ of phase separation corresponded to a subsequent abrupt increase in both intensity and radius.

Computational Methods. Protein electrostatic calculations require identification of effective $\mathrm{p} K_{\mathrm{a}}$ values of ionizable amino acids, ideally obtained via rigorous multidimensional

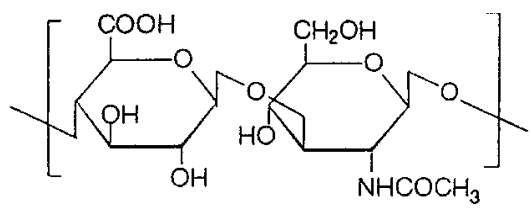

Figure 1. The repeat unit of hyaluronic acid.

NMR analysis; for a large protein such as BSA, such a formidable accomplishment has not been reported. Computational models have been proposed for the calculation of protein $\mathrm{p} K_{\mathrm{a}}$ values ${ }^{39}$ but yield results deviating strongly from NMR data. ${ }^{40}$ On the other hand, Tanford proposed a simple electrostatic model ${ }^{41}$ (subsequently modified by Nagasawa and Holtzer ${ }^{42}$ ) which, in combination with sets of calculated intrinsic $\mathrm{p} K_{\mathrm{a}}$ values, yielded excellent agreement with highly precise titration data for several proteins. Although fundamentally simplistic and lacking in structural detail, this model nevertheless appears to account for electrostatic effects on $\mathrm{p} K_{\mathrm{a}}$ by means of a semiempirical fitting parameter. ${ }^{41}$ These approximations have not yet been verified by NMR, but their success in yielding a near-perfect fit to titration data for serum albumin led us to follow Tanford in assigning $\mathrm{p} K_{\mathrm{a}}$ values.

The structure of human serum albumin was obtained and edited before calculations. Crystal structure 1ao6, ${ }^{43}$ an HSA dimer, was downloaded from the Research Collaboratory for Structural Bioinformatics Protein Data Bank (http:// www.rcsb.org/pdb/). Chain B, identical to chain A, was deleted. Fractional charges ${ }^{44}$ were assigned for each charged amino acid based on a detailed treatment, including a correction for ionic strength, of the highly precise HSA titration data of Tanford, using the following $\mathrm{p} K_{\text {int }}$ values: term-COOH, 3.75; term- $\mathrm{NH}_{2}$, 7.75; Asp, 3.95; Glu, 3.95; His, 6.90; Lys, 9.8; Tyr, 10.35; Arg, 12.0. ${ }^{41 \mathrm{a}}$ Three charged amino acid residues at the $\mathrm{N}$-terminal end of the protein were missing in the pdb file. To account for this, the terminal nitrogen atom was assigned a charge equal to the sum of its actual charge and the three missing charges.

Electrostatic potential was calculated in and around the protein by means of nonlinear solution of the PoissonBoltzmann equation by DelPhi v. 98.0 (Molecular Simulations Inc.). Human serum albumin was positioned in the center of a grid box with its largest dimension occupying $40 \%$ of the grid length. Iterations of the Poisson-Boltzmann calculations to the point of convergence were preceded by assigning potentials to boundary points of the grid box according to Coulomb's law. The resolution was set at 141 grid points per axis. The dielectric constants of the solvent and the protein were set to 80.0 and 2.5 , respectively. The radii of solvent and ions were defined as 1.4 and $2.0 \AA$, respectively. Approximate convergence of the nonlinear Poisson-Boltzmann equation was obtained after 500 iterations. The electrostatic potential was then calculated at every point inside the grid box.

\section{Results and Discussion}

The values of $\mathrm{pH}_{\mathrm{c}}=5.6 \pm 0.1$ and $\mathrm{pH}_{\phi}=4.7$, obtained as shown in Figure 2 by turbidimetric titration at $I=$ 


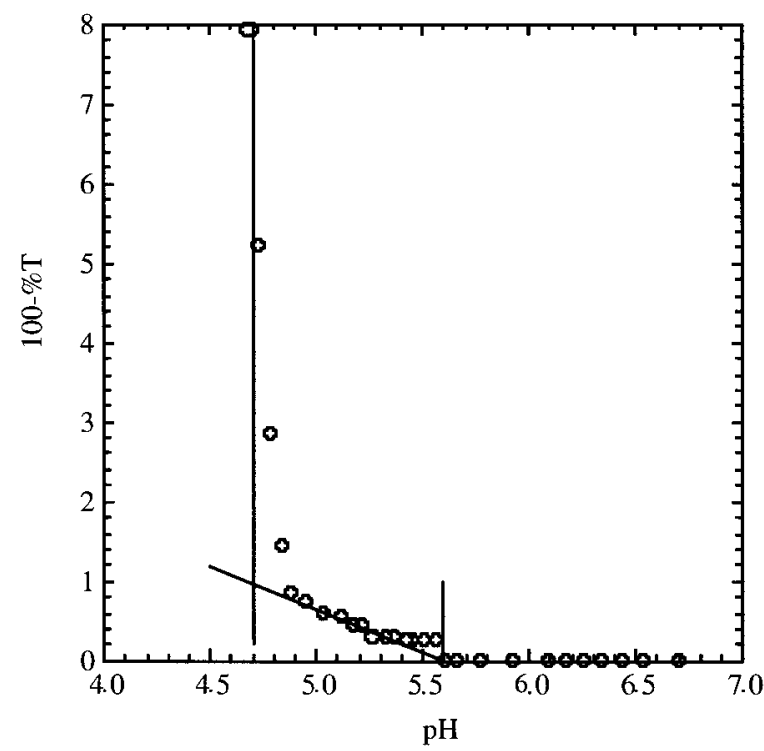

Figure 2. Turbidimetric titration of $B S A(0.5 \mathrm{~g} / \mathrm{L})$ and $\mathrm{HA}(0.05 \mathrm{~g} / \mathrm{L})$ in $0.5 \mathrm{M} \mathrm{NaCl}$.

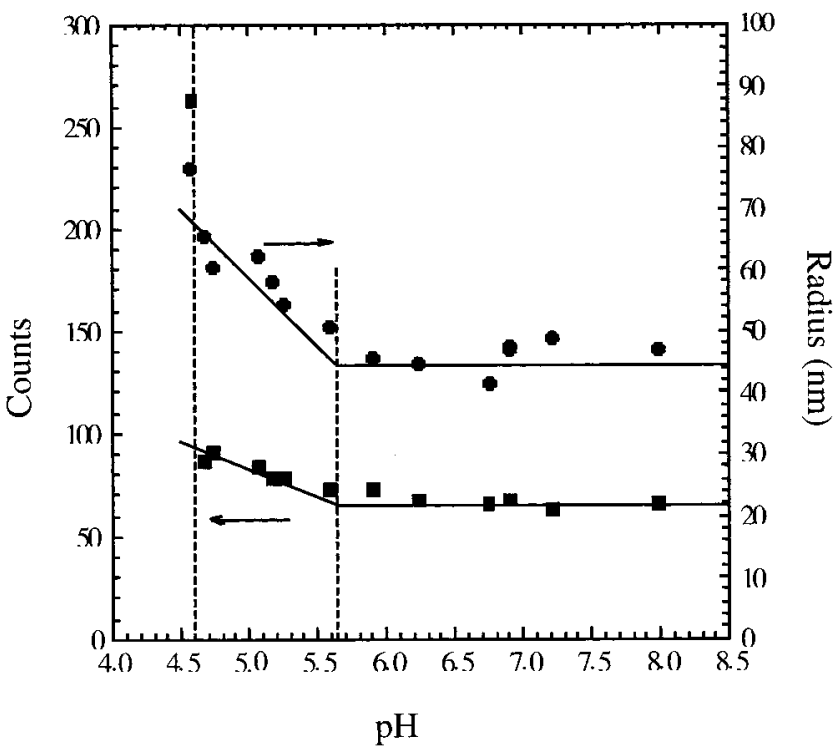

Figure 3. $\mathrm{pH}$ dependence of $(\boldsymbol{\square})$ total count rate and $(\bullet)$ apparent mean Stokes radius from DLS.

$0.05 \mathrm{M}$, are confirmed by DLS as shown in Figure 3. Thus, turbidity, total scattering, and measurement of apparent mean Stokes radii all reveal the formation of a BSA-HA soluble complex at $5.6<\mathrm{pH}_{\mathrm{c}}<5.7$ for this ionic strength. The changes in the transmittance, count rate, and $R_{\mathrm{h}}$ at $\mathrm{pH}_{\mathrm{c}}$ are subtle (but self-consistent and reproducible) and reflect the modest expansion of the chain and enhancement of particle mass upon complexation. The structure of the complex is however not the theme of the current work, which focuses rather on the critical binding conditions.

The ionic strength dependences of $\mathrm{pH}_{\mathrm{c}}$ and $\mathrm{pH}_{\phi}$ are shown in Figure 4, which also includes several data points for the HSA system. Given the congruence of the data for HSA and BSA, the two proteins were considered interchangeable in this study. This was expedient because the structure of BSA is not available on the PDB. Differences between the two proteins are minimal and conservative: the Pro residues at the tips of the five large loops have the same locations in

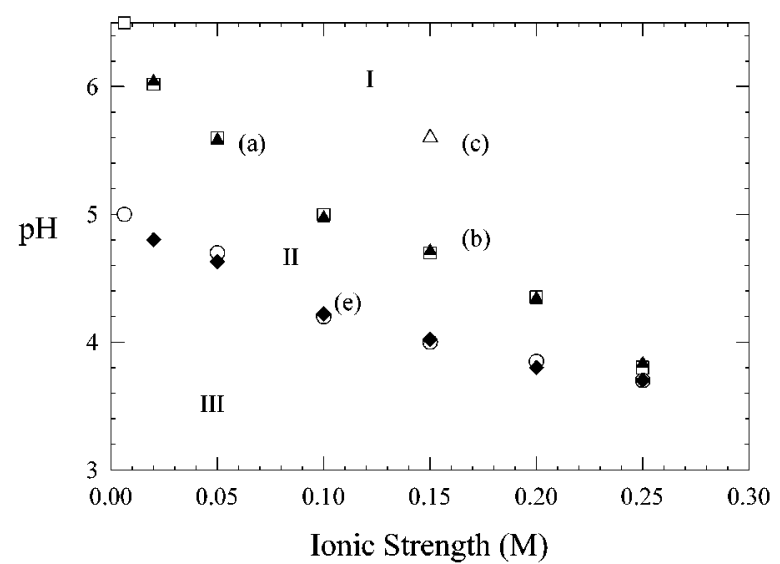

Figure 4. Ionic strength dependence of $\mathrm{pH}_{\mathrm{c}}$ and $\mathrm{pH}_{\phi}$ for $\mathrm{HA}+$ serum albumin: $\mathrm{pH}_{\mathrm{c}},(\square) \mathrm{HSA},(\boldsymbol{\Delta}) \mathrm{BSA}$; $\mathrm{pH}_{\phi},(\mathrm{O}) \mathrm{HSA},(\bullet) \mathrm{BSA}$. Regimes corresponding to the absence of complexation, formation of soluble complexes, and macroscopic phase separation are designated by I, $\mathrm{II}$, and III, respectively. Points a, b, c, and e refer to conditions employed to generate correspondingly labeled images in Figure 7.

both molecules, and every difference in sequence between the two proteins retains the same polarity. ${ }^{45}$

It has been proposed that HA and serum albumin interact at physiological conditions. Laurent and Ogston found that the osmotic pressure of a serum albumin-hyaluronic acid mixture is much higher than the sum of the osmotic pressures of the individual components, suggesting some interaction. ${ }^{46}$ The viscosity of hyaluronic acid undergoes a 3 -fold increase when it is combined with synovial fluid proteins; since albumin is the most concentrated protein in synovial fluid, this increase in viscosity has been attributed to an expansion of hyaluronic acid upon binding albumin. ${ }^{47}$ Rheological changes upon combination of HA with serum albumin have also been noted by Colby and co-workers. ${ }^{48}$ On the other hand, Xu et al. reported deviations from $100 \%$ transmittance for HA/BSA mixtures only for $\mathrm{pH}$ less than 5 , even at ionic strength as low as $1 \mathrm{mM} \cdot{ }^{49}$ As seen in Figure 4, our scattering data also indicate that the soluble complex domain is far from physiological conditions.

Figure 4 reveals domains of incipient binding (the $\mathrm{pH}_{\mathrm{c}}$ "phase boundary"), stronger binding (the region II between $\mathrm{pH}_{\mathrm{c}}$ and $\mathrm{pH}_{\phi}$ ), and nonbinding (the region $\mathrm{I}$ at $\mathrm{pH}>\mathrm{pH}_{\mathrm{c}}$ ). It is expected that electrostatic models of the protein at these various $\mathrm{pH}$ and $I$ conditions should disclose corresponding features. First, if there is an identifiable binding site, computer visualization at any $\mathrm{pH}_{\mathrm{c}}, I$ combination should reveal some consistent feature of the protein potential surface. As a corollary, calculations performed at $\mathrm{pH}<\mathrm{pH}_{\mathrm{c}}$ and/or $I<I_{\mathrm{c}}$ (i.e., conditions of stronger binding) should result in an expansion of the positive potential in this region of the protein surface potential, and vice versa for higher $\mathrm{pH}$ or $I$. Similarly, calculations performed at $\mathrm{pH}>\mathrm{pH}_{\mathrm{c}}$ or $I>I_{\mathrm{c}}$ should disclose diminutions of positive potential.

Ionic strength and $\mathrm{pH}$ conditions for the computer modeling of HSA were selected as follows. First, to avoid the complicating effects of HA charge variation, the $\mathrm{pH}$ was confined to $\mathrm{pH}>4.50(\alpha=1){ }^{31}$ Calculations were then carried out at critical conditions, e.g., $\mathrm{pH}_{\mathrm{c}}=5.60, I=0.05$ M (point a in Figure 4). If a "charge patch" can be correctly identified by computer visualization at point a, that same 


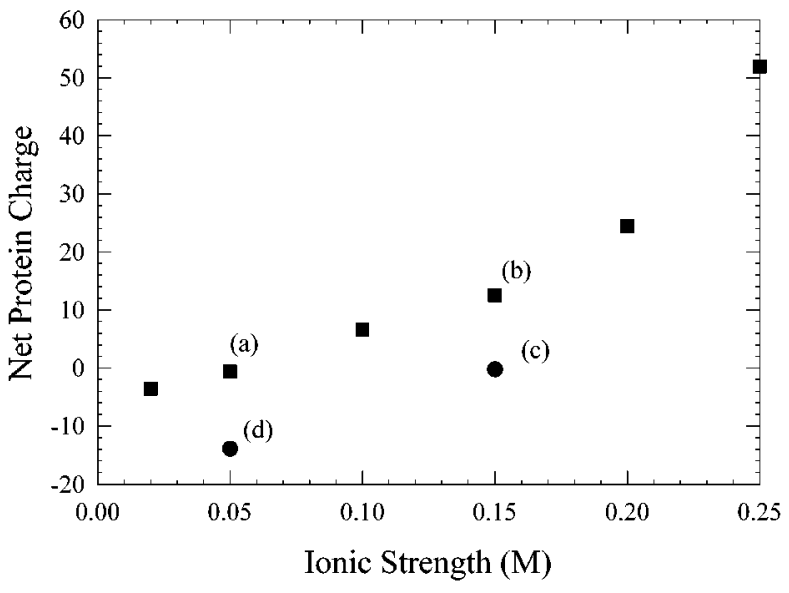

Figure 5. Data of Figure 4 presented as the ionic strength dependence of the net protein charge at critical conditions $\left(Z_{c}\right)$ for complex formation. Points $a, b, c$, and $d$ correspond to conditions used for generating images in Figure 7. Points $d$ and $c$ are in "Regime I" (no complex formation).

patch should be seen at another critical point of incipient complexation, e.g., $\mathrm{pH}_{\mathrm{c}}=4.70, I=0.15 \mathrm{M}$ (point b). Conversely, calculations performed at $\mathrm{pH}<\mathrm{pH}_{\mathrm{c}}$ and/or $I<$ $I_{\mathrm{c}}$ (i.e., conditions of stronger binding) should result in an expansion of positive potential in this region, and vice versa for higher $\mathrm{pH}$ or $I$. To isolate the effects of $I$ and $\mathrm{pH}$ on potential, calculations were also carried out at $\mathrm{pH}=5.60$ and $I=0.15$ (point c), where HSA and HA do not interact with each other; this condition has the same $\mathrm{pH}$ as point a, but a different ionic strength, and the same ionic strength as point $\mathrm{b}$, but a different $\mathrm{pH}$. However, since $\mathrm{pH}$ is not a fundamental charge parameter, another set of conditions was desirable to test the hypothesis that a displacement from the critical curve by a certain change in protein net charge, $\Delta Z$, would have the same effect on potential regardless of $I$. A phase boundary was therefore constructed by plotting $I$ versus $Z_{\mathrm{pr}}$ (Figure 5). Using the conditions of point a as a reference, calculations were carried out at $\mathrm{pH}=7.56, I=0.05$ (point d), corresponding to a change in $Z$ at constant $I$. Note that $Z($ a $)-Z(\mathrm{~d}) \approx Z(\mathrm{~b})-Z(\mathrm{c}) \approx 13$.

The potential around the protein can be displayed in numerous ways. The region with the highest positive electrostatic potential at the surface (region A, centered at Lys 199, see Figure 6) was selected as the primary area for viewing. When the potential was displayed on the surface of the protein, many regions of positive and negative potential appeared, but no extensive positive domain could be observed. Binding at the protein surface is also precluded by the necessity of complete dehydration and the requirement of significant and unrealistic flexibility on the part of the stiff polymer HA (persistence length, $45 \AA^{50}$ ). Therefore, virtual surfaces were created at $x=3,5,7$, and $10 \AA$ from the van der Waals surface. As was the case for $x=0$, potentials at the $x=3 \AA$ surface did not reveal any significant positive domain. Images generated at 7 and $10 \AA$ surfaces failed to show the requisite similarity of "charge patches" at conditions along the phase boundary. The surface at $5 \AA$ provided more reasonable images, best represented by a contour grid at $\psi=+0.05 \mathrm{kT} / \mathrm{e}$ which, as shown in Figure 7 , covered all regions of significant positive electrostatic

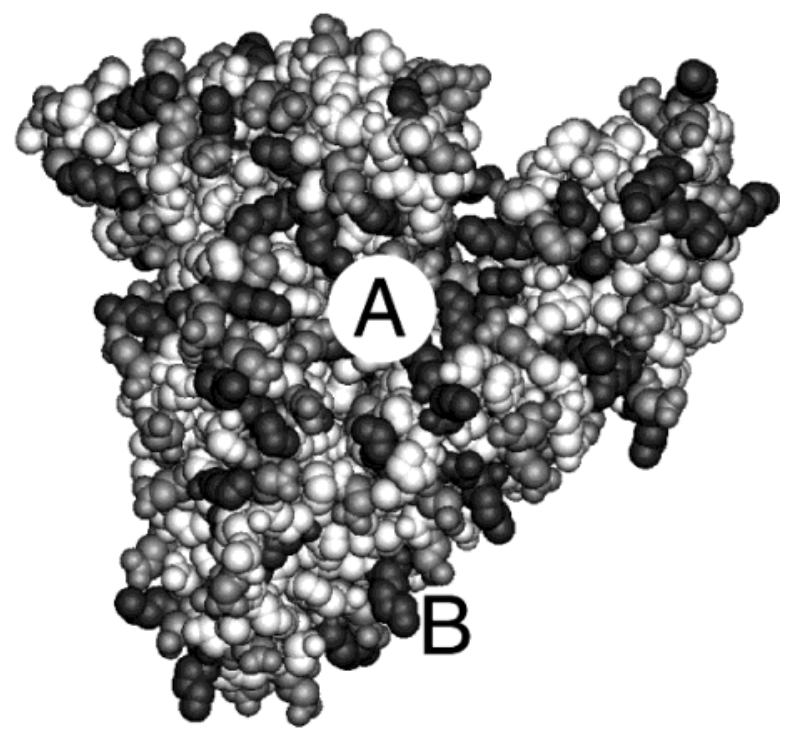

Figure 6. van der Waals surface of HSA indicating locations of two regimes of high positive potential, centered at lys 199 (A) and lys378 (B). Positive, negative, and neutral amino acids are dark gray, light gray, and white, respectively.

potential on the $5 \AA$ surface. Thus the values of $5 \AA$ and $+0.05 \mathrm{kT} / \mathrm{e}$ are those which enable us to test two of the hypotheses put forward in the Introduction, namely, that a "charge patch" that controls HA binding must (1) appear identical at all values of $\mathrm{pH}_{\mathrm{c}}$ regardless of $I$ and (2) must expand or diminish as $\mathrm{pH}$ decreases or increases, respectively. While the selection of this $5 \AA$ surface may imply that complex formation does not require desolvation, this is an inference, not an a priori condition.

The electrostatic domain, centered at Lys 199 ("domain A"), appears essentially identical in the images of HSA obtained at two different critical conditions: $I=0.05 \mathrm{M}$, $\mathrm{pH}_{\mathrm{c}}=5.60$ (point a); and $I=0.15 \mathrm{M}, \mathrm{pH}_{\mathrm{c}}=4.70$ (point b). This large and continuous electrostatic domain of relatively low rugosity becomes diminished and discontinuous in the images corresponding to conditions of no interaction: $I=$ $0.15 \mathrm{M}, \mathrm{pH}=5.60$ (point $\mathrm{c}$ ); and $I=0.05 \mathrm{M}, \mathrm{pH}=7.65$ (point d). On the other hand, at phase separation, $I=0.10$ $\mathrm{M}, \mathrm{pH}_{\phi}=4.20$ (point e), this domain is expanded and intensified, as expected, since phase separation requires that the number of bound proteins multiplied by their mean (negative) charge be sufficient to neutralize the charge on the polycation. ${ }^{30}$ These models show that domain $\mathrm{A}$ at $x=$ $5 \AA$ A satisfies both criteria for determining a preferential region of binding: similarity at $\mathrm{pH}_{\mathrm{c}}$ values, and diminution at noninteraction conditions.

The suggestion that all critical conditions might correspond to a constant potential at some position beyond the van der Waals surface has been previously made based on studies of the binding of synthetic polyanions to positively charged micelles ${ }^{51}$ or synthetic polycations and negatively charge dendrimers. ${ }^{52}$ In the former case, binding was observed when the potential due to the micelle at a distance $6 \AA$ from the micelle surface exceeded $+6 \mathrm{mV}$, regardless of $I .{ }^{51}$ While this system is quite different from the present one, a common fact is that steric constraints limit how closely a polymer can approach a surface of high curvature or rugosity, so that 
(a)

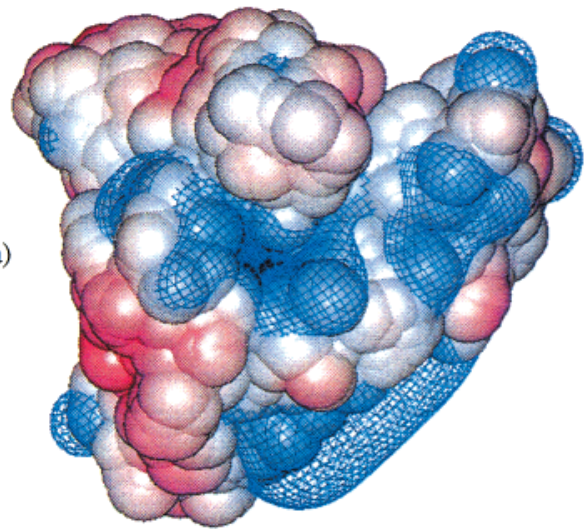

(c)

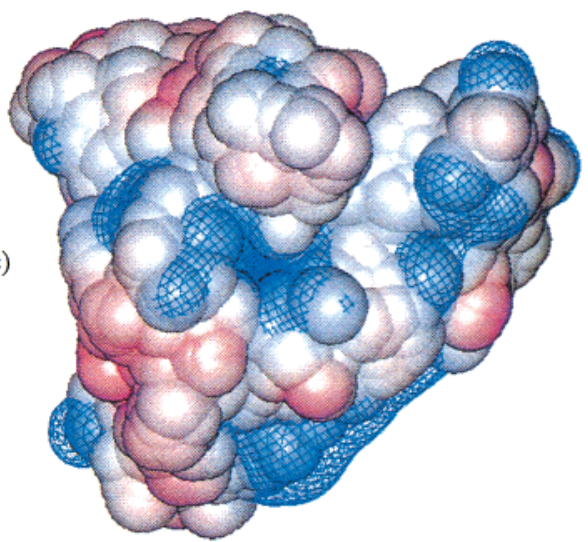

(e)

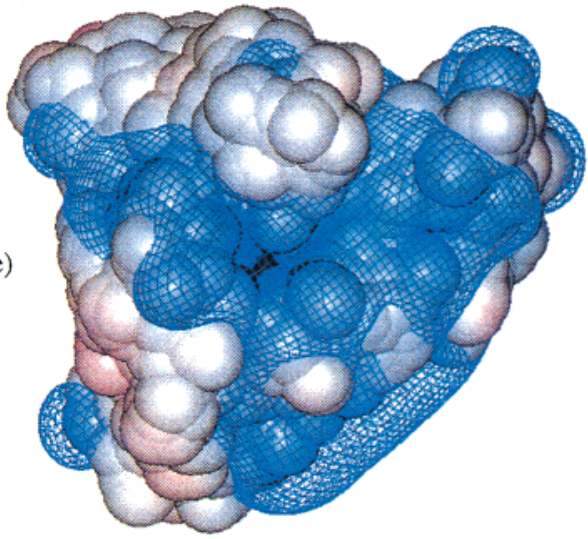

(b)

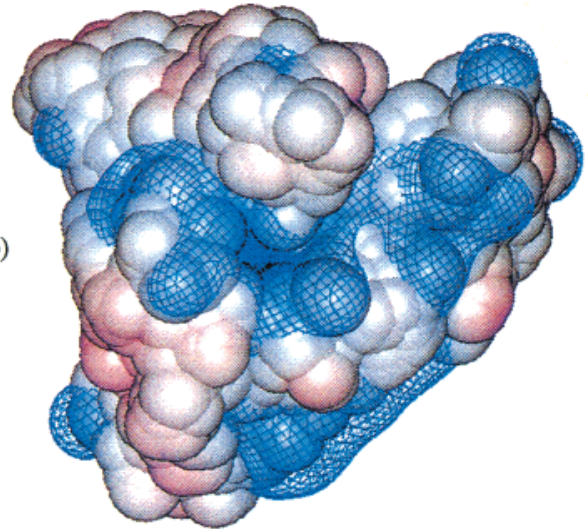

(d)

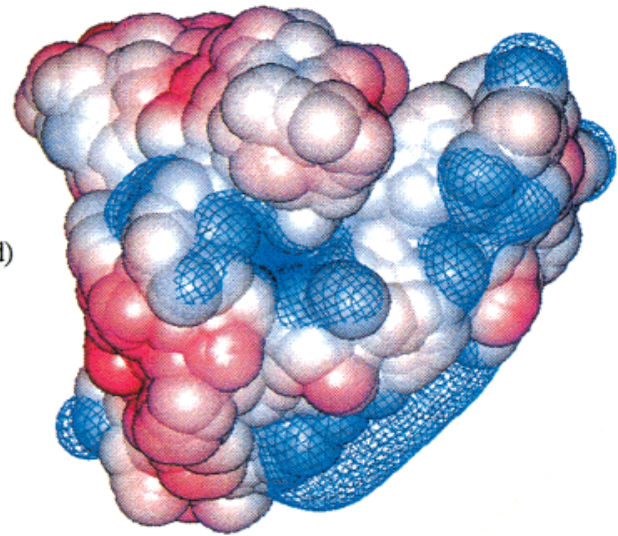

(f)

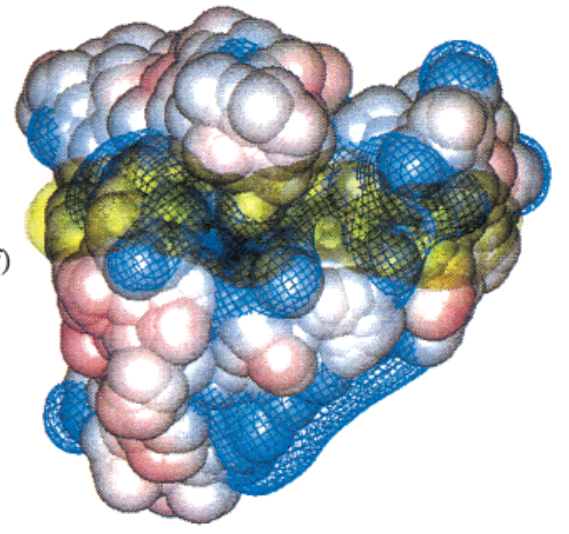

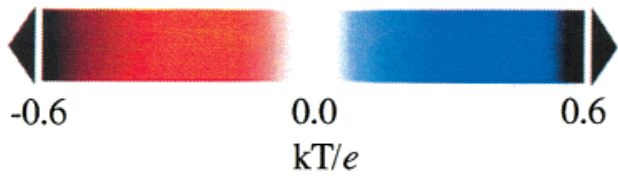

$2 \mathrm{~nm}$

Figure 7. Electrostatic potential surfaces represented as $+0.05 \mathrm{kT} / \mathrm{e}$ contours beyond $5 \AA$ from the van der Waals surface. lonic strength and pH conditions: (a) $0.005 \mathrm{M}, 5.60\left(\mathrm{pH}_{\mathrm{c}}\right)$; (b) $0.15 \mathrm{M}, 4.70\left(\mathrm{pH}_{\mathrm{c}}\right)$; (c) $0.15 \mathrm{M}, 5.60$; (d) $0.05 \mathrm{M}, 7.65$; (e) $0.10 \mathrm{M}, 4.20$ (pH ( $_{\phi}$; (f) same as (b) with decamer of $\mathrm{HA}$ superimposed on suggested electrostatic binding site.

the mean position of bound polymer segments cannot be the protein surface itself. This postulate, which must be especially true for stiff polymers, such as HA, differentiates our approach from most computer modeling efforts, in which the bound state is expected to essentially involve van der Waals contact between host and guest (which of those two is GAG and which protein often considered a matter of viewer discretion).

Although increases in ionic strength and $\mathrm{pH}$ can lead to the same alteration of potential in the binding domain, they do so in different ways. The increase in ionic strength from point a to point $\mathrm{c}$ in Figure 7 causes the potential to decay 
more rapidly. The resulting contraction of the $+0.05 k T / \mathrm{e}$ potential grid surface to regions below $x=5 \AA$ makes the patch visualized in Figure $7 d$ appear discontinuous. On the other hand, the decrease in the absolute value of $Z$ between point $\mathrm{b}$ and point $\mathrm{c}$ corresponds to the presence of more negative charges, which in turn displace some regions of positive potential, also making the patch appear discontinuous.

While the phase boundary defined by points $a$ and $b$ corresponds to the onset of observable binding, we can visualize other boundaries corresponding to internally consistent but lower energy in the "noninteraction region". It is of interest to consider whether such a second boundary might correspond to a displacement by some $\Delta Z$ from the $\mathrm{pH}_{\mathrm{c}}$ boundary. Therefore we constructed images $\mathrm{d}$ and $\mathrm{c}$, which are displaced by equal increments of $Z$ from critical conditions (see Figure 5). The resulting images indeed show a similarity in "domain A".

Although the domain centered at Lys 378 ("domain B") is large and positive, it is not consistent with the two criteria for identification of a binding domain: The appearance of this region varies greatly among different points of critical conditions but changes little when the $\mathrm{pH}$ varies, at either $I$ $=0.05 \mathrm{M}$ or $I=0.15 \mathrm{M}$ (e.g., images $\mathrm{b}$ and $\mathrm{c}$ ). Identification of domain $\mathrm{A}$ rather than domain $\mathrm{B}$ as the binding region is also supported by steric considerations. The curvature of domain $\mathrm{B}$ is appreciably larger than that of domain $\mathrm{A}$, which inhibits the binding of the rather stiff polyanion. It may then be inferred that HA prefers an extended area of low positive potential rather than a smaller, more highly curved area of high positive potential. This is visualized in Figure 7f, which shows superimposed on domain A a decamer of hyaluronic acid obtained by duplication of an optimized disaccharide unit, followed by reoptimization. ${ }^{53}$ As seen in Figure 7f, the polymer lies directly on the patch on the electrostatic surface of domain A and does not need to bend to follow its contour or to avoid regions of negative potential.

Since images $\mathrm{a}$ and $\mathrm{b}$ are generated at conditions corresponding to the onset of binding, we should expect polyelectrolyte-protein binding energies on the order of $1 \mathrm{kT}$. An approximation of the electrostatic binding energy is obtained by multiplying the net charge of the HA binding unit by the mean potential at the binding site. Inspection of Figure 7 a shows that the potential at the $5 \AA$ surface around domain A varies from $+0.05 \mathrm{kT} / \mathrm{e}$ to $+0.3 \mathrm{kT} / \mathrm{e}$, with a mean value of about $+0.1 \mathrm{kT} / \mathrm{e}$. The energy for bringing an HA decamer to that location is therefore ca. $10 e \times 0.1 \mathrm{kT} / \mathrm{e}=1$ $k T$, which lends support to the identification of domain A as the locus of bound HA at critical conditions. While this consistency is gratifying, we should caution against an overly literal interpretation of our identification of an electrostatic domain $5 \AA$ from the protein surface. This may indeed say something about the mean position of bound HA segments but cannot be used to infer much about the freedom of motion of bound HA or the residence time of bound protein. However, because no positive domain can be observed at the 0 or $3 \AA$ surfaces, we can surely conclude that considerations of the localized charges alone would not provide a basis for prediction of a binding location.
The identification of domain A as the "binding site" for $\mathrm{HA}$ is an unconventional one in that it is not located at the protein surface but is quite reasonable since the stiffness of HA precludes its "wrapping around" the protein, much less its penetration into any crevice. Instead, we suggest that the complex is likely to be relatively transient. This form of weak interaction may be consistent with the low-affinity, nonspecific protein binding thought to be intrinsic to some of the functions of glycosaminoglycans. ${ }^{20}$

Since this modeling approach only involves the protein, it may be applicable as well to serum albumin complexation with other polyelectrolytes. A similar approach was indeed recently used to rationalize observations for complex formation between heparin and BSA. ${ }^{54}$ For synthetic polyelectrolytes more flexible than HA, the ability of the polymer to conform to complex charge patterns on the protein surface might mitigate against the identification of a unique binding site. An indication of such an effect of polyanion flexibility is the observation that BSA binds less strongly to hyaluronic acid than to copolymers of acrylamide and AMPS (2acrylamido-2-methylpropanesulfonate) with the same linear charge density as HA. ${ }^{55}$

\section{Conclusions}

Calculations of the electrostatic potential around human serum albumin (HSA) were carried out at $\mathrm{pH}$ and ionic strength conditions corresponding to (a) phase separation, (b) incipient binding, and (c) noninteracting conditions for the system HSA + hyaluronic acid (HA). These conditions were established by dynamic light scattering and turbidimetry. Visualization of the electrostatic domain centered at Lys 199 and located $5 \AA$ from the van der Waals surface reveals that this domain is invariant with respect to $\mathrm{pH}$ and/ or $I$ at $\mathrm{pH}$ and $I$ conditions of incipient complex formation. This same domain diminishes at noninteracting conditions and expands at conditions of phase separation. Its geometry readily accommodates the binding of an HA decamer, in contrast to other, more highly curved positive regions. The electrostatic binding energy of the decamer at $\mathrm{pH}_{\mathrm{c}}$ is approximately $1 k T$, consistent with the onset of complex formation.

Acknowledgment. Support from the National Science Foundation under Grant CHE-9987891 is acknowledged, as is the assistance of Dr. Daniel Robertson of the Center for Computational Modeling of IUPUI.

\section{References and Notes}

(1) Rouzina, I.; Bloomfield, V. A. J. Phys. Chem. 1996, 100, 4305

(2) (a) Morawetz, H.; Hughes, W. L. J. Phys. Chem. 1952, 56, 64. (b) Samsonov, G. V.; Ponomareva, R. B.; Luchko, R. G. Biophysika 1969, 14, 634. (c) Kabanov, V. A.; Evdkov, V. P.; Mustafaev, M. I.; Antipina, A. D. Mol. Biol. 1977, 11, 582. (d) Kokufuta, E.; Shimizu, H.; Nakamura, I. Macromolecules 1981, 15, 1618.

(3) (a) Sternberg, M.; Hershberger, D. Biochim. Biophys. Acta 1974, 342, 195. (b) Sternberg, M. Process Biochem. 1976, 11, 11. (c) Clark, K. M.; Glatz, C. E. In Downstream Processing and Bioseparation. Recovery and Purification of Biological Products; Hamel, J.-F., Hunter, J. B., Sikdar, S. K., Eds.; American Chemical Society: Washington, DC, 1990; Chapter 9. (d) Strege, M. A.; Dubin, P. L.; West, J. S.; Flinta, C. D. In Protein Purification: from Molecular 
Mechanisms to Large-Scale Processes; Ladisch, M., Wilson, R. C., Painton, C. C., Builder, S. E., Eds.; American Chemical Society: Washington, DC, 1990; Chapter 5. (e) Wang, Y.; Gao, J. Y.; Dubin, P. L. Biotechnol. Prog. 1996, 12, 356.

(4) (a) Margolin, A. L.; Sherstyuk, S. F.; Izumrudov, V. A.; Zezin, A. B.; Kabanov, V. A. Eur. J. Biochem. 1985, 146, 625. (b) Kokufuta, E. Prog. Polym. Sci. 1992, 16, 647. (c) Xia, J.; Dubin, P. L.; Mattison, K.; Romano, V.; Muhoberac, B. B Biopolymers 1997, 41, 359.

(5) (a) Brynda, E.; Houska, M. J. Colloid Interface Sci. 1996, 183, 18. (b) Hughes-Wassell, Brynda, E.; Houska, M. J. Colloid Interface Sci. 1996, 183, 18. (b) Hughes-Wassell, D. T.; Embery, G. Biomaterials 1997, 18, 1121. (c) Caruso, F.; Niikura, K.; Furlong, D. N.; Okahata, Y. Langmuir 1997, 13, 3427. (d) Franchina, J. G.; Lackowski, W. M.; Dermody, D. L.; Crooks, R. M.; Bergbreiter, D. E.; Sirkar, K.; Russell, R. J.; Pishko, M. V. Anal. Chem. 1999, 71, 3133.

(6) Masse, J. E.; Allain, F. H-T.; Yen, Y.-M.; Johnson, R. C.; Feigon, J. J. Am. Chem. Soc. 1999, 121, 3547.

(7) Lao, Y.; Gomes, X. V.; Ren, Y.; Taylor, J.-S.; Wold, M. S. Biochemistry 2000, 39, 850

(8) Lannutti, B. J.; Persinger, J.; Bartholomew, B. Biochemistry 1996, $35,9821$.

(9) (a) Lorenz, M.; Hillisch, A.; Payet, D.; Buttinelli, M.; Travers, A.; Diekman, S. Biochemistry 1999, 38, 12150. (b) Jezewska, M. J.; Kim, U.-S.; Bujalowski, W. Biochemistry 1996, 35, 2129.

(10) Ottinger, L. M.; Tullius, T. D. J. Am. Chem. Soc. 2000, 122, 5901

(11) Xia, J.; Dubin, P. L. In Macromolecular Complexes in Chemistry and Biology; Dubin, P. L., Bock, J., Davis, R., Schultz, D., Eds.; Springer-Verlag: Berlin, 1995.

(12) Xia, J.; Muhoberac, B.; Dubin, P. L.; Kokufuta, E.; Havel, H. Biopolymers 1999, 50, 153.

(13) Yamaguchi, K.; Hachiya, K.; Moriyama, Y.; Takeda, K. J. Colloid Interface Sci. 1996, 179, 249.

(14) Sato, T.; Mattison, K. W.; Dubin, P. L.; Kamachi, M.; Morishima, Y. Langmuir 1998, 14, 5430.

(15) (a) Yun, J. H.; Ma, S.; Fu, B.; Yang, V. C.; Meyerhoff, M. E. Electroanalysis 1993, 5, 719. (b) Wen, Y.-P.; Dubin, P. L. Macromolecules 1997, 30, 7856.

(16) (a) Gao, J. Y.; Dubin, P. L.; Muhoberac, B. B. Anal. Chem. 1997, 69, 2945. (b) Hallberg, R.; Dubin, P. L. J. Phys. Chem. 1998, 102 , 8629.

(17) Darnell, J.; Lodish, H.; Baltimore, D. Molecular Cell Biology; W. H. Freeman: New York, 1990; Chapter 23.

(18) Iozzo, R. V. Matrix Proteoglycans: from Molecular Design to Cellular Function. Annu. Rev. Biochem. 1998, 67, 609.

(19) Iozzo, R. V.; Murdoch, A. D. FASEB J. 1996, 10, 598

(20) Lander, A. D. Matrix Biol. 1998, 17, 465.

(21) Lindahl, U.; Backström, G.; Thunberg, L.; Leder, I. G. Proc. Natl. Acad. Sci. U.S.A. 1980, 77, 6551.

(22) Faham, S.; Hileman, R. E.; Fromm, J. R.; Linhardt, R. J.; Rees, D. C. Science 1996, 271, 1116 .

(23) Winterton, L. C.; Andrade, J. P.; Feijen, J.; Kim, S. W. J. Colloid Interface Sci. 1986, 111, 314.

(24) (a) Xia, J.; Dubin, P. L.; Kim, Y.; Muhoberac, B. B.; Klimkowski, V. J. Phys. Chem. 1993, 97, 4528. (b) Mattison, K. W.; Dubin, P. L.; Brittain, I. J. J. Phys. Chem. 1998, 102, 3830

(25) Record, T. M.; Lohman, T. M.; de Haseth, P. J. Mol. Biol. 1976, 107, 145.

(26) (a) Faller, B.; Mely, Y.; Gerard, D.; Bieth, J. G. Biochemistry 1992, 31, 8285. (b) Mascotti, D.; Lohman, T. M. Biochemistry 1995, 34, 2908.

(27) Moskowitz, R. W.; Howell, D. S.; Goldberg, V. M.; Mannkin, H. J. Osteoarthritis: Diagnosis and Medical/Surgical Management, 2nd ed.; W.B. Saunders: Philadelphia, PA, 1992; p $200 f f$.
(28) (a) Olsten, A. G.; Stonier, J. E. Biochem. J. 1952, 52, 149. (b) Palfrey, A. J.; White, J. B. Biorheology 1968, 5, 189.

(29) Sato, T.; Mattison, K. W.; Dubin, P. L.; Kamachi, M.; Morishima, Y. Langmuir 1998, 14, 5430.

(30) Li, Y.; Mattison, K. W.; Havel, H. A.; Edwards, S. L. Biopolymers 1996, 38, 527 .

(31) Cleland, R. L.; Wang, J. L.; Detweiler, D. M. Macromolecules 1982, 15,386

(32) Regnier, F. E. Science 1987, 238, 319.

(33) Bitomsky, W.; Wade, R. C. J. Am. Chem. Soc. 1999, 121, 3004.

(34) (a) Cleland, R. L. Arch. Biochem. Biophys. 1977, 180, 57. (b) Ghosh, S.; Li, X.; Reed, C. E.; Reed, W. F. Biopolymers 1990, 30, 1101

(35) Gilson, M. K.; Sharp, K. A.; Honig, B. H. J. Comput. Chem. 1987, 9, 327.

(36) Honig, B.; Nicholls, A. Science 1995, 268, 1146.

(37) Hecht, J. L.; Honig, B.; Shin, Y.; Hubbell, W. L. J. Phys. Chem. 1995, 99, 7782.

(38) Berman, H. M.; Westbrook, J.; Feng, Z.; Gilliland, G.; Bhat, T. N.; Weissing, H.; Shindyalov, I. N.; Bourne, P. E. Nucleic Acids Res. 2000, 28, 235.

(39) (a) Antosiewicz, J.; McCammon, J. A.; Gilson, M. K. Biochemistry 1996, 35, 7819. (b) Juffer, A. H. Biochem. Cell Biol. 1998, 76, 198 (c) Juffer, A. H.; Argos, P.; Vogel, H. J. J. Phys. Chem. B 1997, 101, 7664. (d) Bashford, D.; Karplus, M. Biochemistry 1990, 29, 10219.

(40) (a)Forsyth, W. R.; Gilson, M. K.; Antosiewicz, J.; Jaren, O. R.; Robertson, A. D. Biochemistry 1998, 37, 8643. (b) Bashford, D.; Case, D. A.; Dalvit, C.; Tennant, L.; Wright, P. E. Biochemistry 1993, 32, 8045. (c) Khare, D.; Alexander, P.; Antosiewicz, J.; Bryan, P.; Gilson, M.; Orban, J. Biochemistry 1997, 36, 3580.

(41) (a) Tanford, C.; Swanson, S. A.; Shore, W. S. J. Am. Chem. Soc. 1955, 77, 6414. (b) Tanford, C.; Wagner, M. L. J. Am. Chem. Soc. 1954, 76, 3331. (c) Tanford, C.; Epstein, J. J. Am. Chem. Soc. 1954 76,2163

(42) Nagasawa, M.; Holtzer, A. J. Am. Chem. Soc. 1971, 93, 606.

(43) PDB ID: 1ao6. Carter, D. C.; Ho, J. X. Adv. Protein Chem. 1994 $45,153$.

(44) This study solely considers uncompensated charges, rather than partial charges. At a distance of $5 \AA$ from the protein, corresponding to the mean position of bound HA deduced in this work, dipole interactions are insignificant, so only screened Coulombic interactions are taken into account.

(45) Brown, J. R.; Shockley, P. In Lipid-Protein Interactions; Jost, P. C., Griffiths, O. H., Eds.; Wiley: New York, 1982; Vol. 1, Chapter 2.

(46) Laurent, T. C.; Ogston, A. G. Biochem. J. 1963, 89, 249.

(47) Tirtaamadja, V.; Boger, D. V.; Fraser, J. R. E. Rheol. Acta 1984, 23, 311.

(48) Krause, W. E. Ph.D. Thesis, The Pennsylvania State University, 2000.

(49) Xu, S.; Yamanaka, J.; Sato, S.; Miyama, I.; Yonese, M. Chem. Pharm. Bull. 2000, 48, 779 .

(50) Comper, W. D.; Laurent, T. C. Physiol. Rev. 1978, 58, 255.

(51) Dubin, P. L.; McQuigg, D. W.; Kaplan, J. I. J. Phys. Chem. 1995 99, 7782

(52) Zhang, H.; Ray, J.; Manning, G. S.; Newkome, G. R.; Moorefield, C. S. J. Phys. Chem. 1999, 103, 2347.

(53) Builder Module, Insight II, v. 98.0, Molecular Simulations, Inc.

(54) Hattori, T.; Kimura, K.; Emek, S.; Dubin, P. L. Anal. Biochem., in press.

(55) Staggemeier, B. Thesis, Purdue University, 1999.

BM005656Z 